\title{
The Social Amplification of Risk: A Conceptual Framework
}

\author{
Roger E. Kasperson, ${ }^{1}$ Ortwin Renn, ${ }^{1}$ Paul Slovic, ${ }^{2}$ Halina S. Brown, ${ }^{1}$ Jacque Emel, ${ }^{1}$ \\ Robert Goble, ${ }^{1}$ Jeanne X. Kasperson, ${ }^{1,3}$ and Samuel Ratick ${ }^{1}$
}

Received October 8, 1987; revised January 8, 1988

\begin{abstract}
One of the most perplexing problems in risk analysis is why some relatively minor risks or risk events, as assessed by technical experts, often elicit strong public concerns and result in substantial impacts upon society and economy. This article sets forth a conceptual framework that seeks to link systematically the technical assessment of risk with psychological, sociologi$\mathrm{cal}$, and cultural perspectives of risk perception and risk-related behavior. The main thesis is that hazards interact with psychological, social, institutional, and cultural processes in ways that may amplify or attenuate public responses to the risk or risk event. A structural description of the social amplification of risk is now possible. Amplification occurs at two stages: in the transfer of information about the risk, and in the response mechanisms of society. Signals about risk are processed by individual and social amplification stations, including the scientist who communicates the risk assessment, the news media, cultural groups, interpersonal networks, and others. Key steps of amplifications can be identified at each stage. The amplified risk leads to behavioral responses, which, in turn, result in secondary impacts. Models are presented that portray the elements and linkages in the proposed conceptual framework.
\end{abstract}

KEY WORDS: Risk; risk perception; social amplification; technological controversies; public participation.

\section{RISK IN MODERN SOCIETY}

The investigation of risks is at once a scientific activity and an expression of culture. During the twentieth century, massive governmental programs and bureaucracies aimed at assessing and managing risk have emerged in advanced industrial societies. Despite the expenditure of billions of dollars and steady improvements in health, safety, and longevity of life, people view themselves as more rather than less vulnerable to the dangers posed by technology.

${ }^{1}$ CENTED, Clark University, Worcester, Massachusetts 01610. ${ }^{2}$ Decision Research, 1201 Oak Street, Eugene, Oregon 97401.

${ }^{3}$ Alan Shawn Feinstein World Hunger Program, Box 1831 Brown University, Providence, Rhode Island 02912.
Particularly perplexing is that even risk events with minor physical consequences often elicit strong public concern and produce extraordinarily severe social impacts, at levels unanticipated by conventional risk analysis.

Several difficult issues require attention:

- The technical concept of risk focuses narrowly on the probability of events and the magnitude of specific consequences. Risk is usually defined by multiplication of the two terms, assuming that society should be indifferent toward a low-consequence/high-probability risk and a high-consequence/lowprobability risk with identical expected values. Studies of risk perception have re- 
vealed clearly, however, that most persons have a much more comprehensive conception of risk. Clearly, other aspects of the risk such as voluntariness, personal ability to influence the risk, familiarity with the hazard, and the catastrophic potential shape public response. $^{(1.2)}$ As a result, whereas the technical assessment of risk is essential to decisions about competing designs or materials, it often fails to inform societal choices regarding technology. ${ }^{(3)}$

- Cognitive psychologists and decision researchers have investigated the underlying patterns of individual perception of risk and identified a series of heuristics and biases that govern risk perception. ${ }^{(4,5)}$ Whereas some of these patterns of perception contrast with the results of formal reasoning, others involve legitimate concern about risk characteristics that are omitted, neglected, or underestimated by the technical concept of risk. In addition, equity issues, the circumstances surrounding the process of generating risk, and the timeliness of management response are considerations, important to people, that are insufficiently addressed by formal probabilistic risk analysis. ${ }^{(6,7)}$

- Risk is a bellwether in social decisions about technologies. Since the resolution of social conflict requires the use of factual evidence for assessing the validity and fairness of rival claims, the quantity and quality of risk are major points of contention among participating social groups. As risk analysis incorporates a variety of methods to identify and evaluate risks, various groups present competing evidence based upon their own perceptions and social agenda. The scientific aura surrounding risk analysis promotes the allocation of substantial effort to convincing official decision makers, and the public, that the risk assessment performed by one group is superior in quality and scientific validity to that of others. Controversy and debate exacerbate divergences between expert and public assessment and often erode confidence in the risk decision process. ${ }^{(8,9)}$

In short, the technical concept of risk is too narrow and ambiguous to serve as the crucial yardstick for policy making.
Public perceptions, however, are the product of intuitive biases and economic interests and reflect cultural values more generally. The overriding dilemma for society is, therefore, the need to use risk analysis to design public policies on the one hand, and the inability of the current risk concepts to anticipate and explain the nature of public response to risk on the other. After a decade of research on the public experience of risk, no comprehensive theory exists to explain why apparently minor risk or risk events, ${ }^{4}$ as assessed by technical experts, sometimes produce massive public reactions, accompanied by substantial social and economic impacts and sometimes even by subsequently increased physical risks. Explaining this phenomenon, and making the practice of risk analysis more sensitive to it, is one of the most challenging tasks confronting the societal management of risk. This paper takes up that challenge.

The explanations that have emerged, while affording important insights, have been partial and often conflicting. The past decade has witnessed debates between the "objectivist and subjectivist" schools of thought, between structuralistic and individualistic approaches, between physical/life scientists and social scientists. Even within the social sciences, psychologists see the roots of explanation in individual cognitive behavior, ${ }^{(10)}$ a claim extensively qualified by anthropologists, who insist that social context and culture shape perceptions and cognition, ${ }^{(11,12)}$ and by analysts of technological controversies, who see "stakeholder" interaction and competing values as the keys. ${ }^{(13)}$ The assumption underlying these debates is that the interpretations are mutually invalidating. In fact, we shall argue, the competing perspectives illuminate different facets of the public experience of risk.

A comprehensive theory is needed that is capable of integrating the technical analysis of risk and the cultural, social, and individual response structures that shape the public experience of risk. The main thesis of this article is that risk events interact with psychological, social, and cultural processes in ways that can heighten or attenuate public percep-

\footnotetext{
${ }^{4}$ In this article, the term " risk event" refers to occurrences that are manifestations of the risk and that initiate signals pertaining to the risk. Risk events thus include routine or unexpected releases, accidents (large and small), discoveries of pollution incidents, reports of exposures, or adverse consequences. Usually such risk events are specific to particular times and locations.
} 
tions of risk and related risk behavior. Behavioral patterns, in turn, generate secondary social or economic consequences but may act also to increase or decrease the physical risk itself. Secondary effects trigger demands for additional institutional responses and protective actions, or, conversely (in the case of risk attenuation), impede needed protective actions. The social structures and processes of risk experience, the resulting repercussions on individual and group perceptions, and the effects of these responses on community, society, and economy compose a general phenomenon that we term the social amplification of risk. This article sets forth an initial conceptualization of the elements, structure, and processes that make up this phenomenon.

\section{BACKGROUND}

The technical assessment of risk typically models the impacts of an event or human activity in terms of direct harms, including death, injuries, disease, and environmental damages. Over time, the practice of characterizing risk by probability and magnitude of harm has drawn fire for neglecting equity issues in relation to time (future generations), space (the so-called LULU or NIMBY issue), or social groups (the proletariat, the highly vulnerable, export of hazard to developing countries). It also has become apparent that the consequences of risk events extend far beyond direct harms to include significant indirect impacts (e.g., liability, insurance costs, loss of confidence in institutions, or alienation from community affairs). ${ }^{(14)}$ The situation becomes even more complex when the analysis also addresses the decision-making and risk-management process. Frequently, indirect impacts appear to be dependent less on the direct outcomes (i.e., injury or death) of the risk event than on judgments of the adequacy of institutional arrangements to control or manage the risk, the possibility of assigning blame to one of the major participants, and the perceived fairness of the risk-management process.

The accident at the Three Mile Island (TMI) nuclear reactor in 1979 demonstrated dramatically that factors besides injury, death, and property damage can impose serious costs and social repercussions. No one is likely to die from the release of radioactivity at TMI, but few accidents in U.S. history have wrought such costly societal impacts. The accident devastated the utility that owned and oper- ated the plant and imposed enormous costs--in the form of stricter regulations, reduced operation of reactors worldwide, greater public opposition to nuclear power, and a less viable role for one of the major long-term energy sources-on the entire nuclear industry and on society as a whole. ${ }^{(15)}$ This mishap at a nuclear power plant may even have increased public concerns about other complex technologies, such as chemical manufacturing and genetic engineering.

The point is that traditional cost-benefit and risk analyses neglect these higher-order impacts and thus greatly underestimate the variety of adverse effects attendant on certain risk events (and thereby underestimate the overall risk from the event). In this sense, social amplification provides a corrective mechanism by which society acts to bring the technical assessment of risk more in line with a fuller determination of risk. At the other end of the spectrum, the relatively low levels of interest by the public in the risks presented by such well-documented and significant hazards as indoor radon, smoking, driving without seat belts, or highly carcinogenic aflatoxins in peanut butter serve as examples of the social attenuation of risk. Whereas attenuation of risk is indispensible in that it allows individuals to cope with the multitude of risks and risk events encountered daily, it also may lead to potentially serious adverse consequences from underestimation and underresponse. Thus both social amplification and attenuation, through serious disjunctures between expert and public assessments of risk and varying responses among different publics, confound conventional risk analysis.

In some cases, the societal context may, through its effects on the risk assessor, alter the focus and scope of risk assessment. A case in point is the series of actions taken in 1984 by the Environmental Protection Agency with regard to a soil and grain fumigant, ethylene dibromide (EDB). ${ }^{(16)}$ An atmosphere charged with intense societal concern about protecting the nation's food and groundwater supplies from chemical contaminants prompted the Agency to focus primarily on these two pathways of population exposure to EDB, although it was well aware that emissions of EDB from leaded gasoline were a significant source of population exposure. Consequently, the first-line receivers of the risk information-the risk managers, the mass media, the politicians, and the general public-heard from the start about cancer risks from tainted water and food, 
but not from ambient air. This example illustrates how the filtering of information about hazards may start as early as in the risk assessment itself and may profoundly alter the form and content of the risk information produced and conveyed by technical experts. ${ }^{(16)}$

Other researchers have noted that risk sources create a complex network of direct and indirect effects that are susceptible to change through social responses. ${ }^{(9,17)}$ But because of the complexity and the transdisciplinary nature of the problem, an adequate conceptual framework for a theoretically based and empirically operational analysis is still missing. The lack of an integrative theory that provides guidelines on how to model and measure the complex relationships among risk, risk analysis, social response, and socioeconomic effects has resulted in a reaffirmation of technical risk assessment, which at least provides definite answers (however narrow or misleading) to urgent risk problems.

The concept of social amplification of risk can, in principle, provide the needed theoretical base for a more comprehensive and powerful analysis of risk and risk management in modern societies. At this point, we do not offer a fully developed theory of social amplification of risk, but we do propose a fledgling conceptual framework that may serve to guide ongoing efforts to develop, test, and apply such a theory to a broad array of pressing risk problems. Since the metaphor of amplification draws upon notions in communications theory, we begin with a brief examination of its use in that context.

\section{SIGNAL AMPLIFICATION IN COMMUNICATIONS THEORY}

In communications theory, amplification denotes the process of intensifying or attenuating signals during the transmission of information from an information source, to intermediate transmitters, and finally to a receiver ${ }^{(18)}$ An information source sends out a cluster of signals (which form a message) to a transmitter, or directly to the receiver. The signals are decoded by the transmitter or receiver so that the message can be understood. Each transmitter alters the original message by intensifying or attenuating some incoming signals, adding or deleting others, and sending a new cluster of signals on to the next transmitter or the final receiver where the next stage of decoding occurs.
The process of transmitting is more complex than the electronic metaphor implies. Messages have a meaning for the receiver only within a sociocultural context. Sources and signals are not independent entities but are perceived as a unit by the receiver who links the signal to the sources or transmitters and draws inferences about the relationship between the two. In spite of the problems of the sourcereceiver model, the metaphor is still powerful enough to serve as a heuristic framework for analyzing communication processes. In a recent literature review of 31 mass-communication textbooks, the sourcereceiver metaphor was, along with the concept of symbolic meaning, the predominant theoretical framework. ${ }^{(19)}$

Each message may contain factual, inferential, value-related, and symbolic meanings. ${ }^{(20)}$ The factual information refers to the content of the message (e.g., the emission of an air pollutant is $X \mathrm{mg}$ per day) as well as the source of the message (e.g., EPA conducted the measurement). The inferential message refers to the conclusions that can be drawn from the presented evidence (e.g., the emission poses a serious health threat). Then those conclusions may undergo evaluation according to specific criteria (e.g., the emission exceeds the allowable level). In addition, cultural symbols may be attached that evoke specific images (e.g., "big business," "the military-industrial complex," "high technology," etc.) that carry strong value implications.

Communication studies have demonstrated that the symbols present in messages are key factors in triggering the attention of potential receivers and in shaping their decoding processes. ${ }^{(21)}$ If, for example, the communication source is described as an independent scientist, or a group of Nobel laureates, the content of the message may well command public attention. Messages from such sources may successfully pass through the selection filters of the transmitters or receivers and be viewed as credible. A press release by the nuclear industry, by contrast, may command much less credibility unless other aspects of the message compensate for doubts about the impartiality of the source.

Transmitters of signals may detect amplification arising from each message component. ${ }^{(22)} \mathrm{A}$ factual statement repeated several times, especially if by different sources, tends to elicit greater belief in the accuracy of the information. An elaborate description of the inference process may distract attention from the accuracy of the underlying assumptions. 
Reference to a highly appreciated social value may increase the receiver's tolerance for weak evidence. And, of course, a prestigious communication source can (at least in the short run) compensate for trivial factual messages. But adding or deleting symbols may well be the most powerful single means to amplify or attenuate the original message.

Amplification of signals occurs during both transmission and reception. The transmitter structures the messages that go to a receiver. The receiver, in turn, interprets, assimilates, and evaluates the messages. But a transmitter, it should be noted, is also a new information source-one that transcribes the original message from the source into a new message and sends it on to the receiver, according to institutional rules, role requirements, and anticipated receiver interests. Signals passing through a transmitter may therefore, be amplified twice-during the reception of information and in recoding.

Signal amplification in communications, then, occupies a useful niche in the overall structure of the social amplification of risk. A discussion of the proposed conceptional framework takes up the next section of this paper.

\section{A STRUCTURAL DESCRIPTION OF THE SOCIAL AMPLIFICATION OF RISK}

Social amplification of risk denotes the phenomenon by which information processes, institutional structures, social-group behavior, and individual responses shape the social experience of risk, thereby contributing to risk consequences (Fig. 1). The interaction between risk events and social processes makes clear that, as used in this framework, risk has meaning only to the extent that it treats how people think about the world and its relationships. Thus there is no such thing as "true" (absolute) and "distorted" (socially determined) risk. Rather the information system and characteristics of public response that compose social amplification are essential elements in determining the nature and magnitude of risk. We begin with the information system.

Like a stereo receiver, the information system may amplify risk events in two ways:

- By intensifying or weakening signals that are part of the information that individuals and social groups receive about the risk;
- By filtering the multitude of signals with respect to the attributes of the risk and their importance.

Signals arise through direct personal experience with a risk object or through the receipt of information about the risk object. ${ }^{(18)}$ These signals are processed by social, as well as individual, amplification "stations," which include the following:

- The scientist who conducts and communicates the technical assessment of risk;

- The risk-management institution;

- The news media;

- Activist social organizations;

- Opinion leaders within social groups;

- Personal networks of peer and reference groups;

- Public agencies.

Social amplification stations generate and transmit information via communications channels (media, letters, telephones, direct conversations). In addition, each recipient also engages in amplification (and attenuation) processes, thereby acting as an amplification station for risk-related information. We hypothesize that the key amplification steps consist of the following:

- Filtering of signals (e.g., only a fraction of all incoming information is actually processed);

- Decoding of the signal;

- Processing of risk information (e.g., the use of cognitive heuristics for drawing inferences);

- Attaching social values to the information in order to draw implications for management and policy;

- Interacting with one's cultural and peer groups to interpret and validate signals;

- Formulating behavioral intentions to tolerate the risk or to take actions against the risk or risk manager;

- Engaging in group or individual actions to accept, ignore, tolerate, or change the risk.

A full-fledged theory of the social amplification of risk should ultimately explain why specific risks 


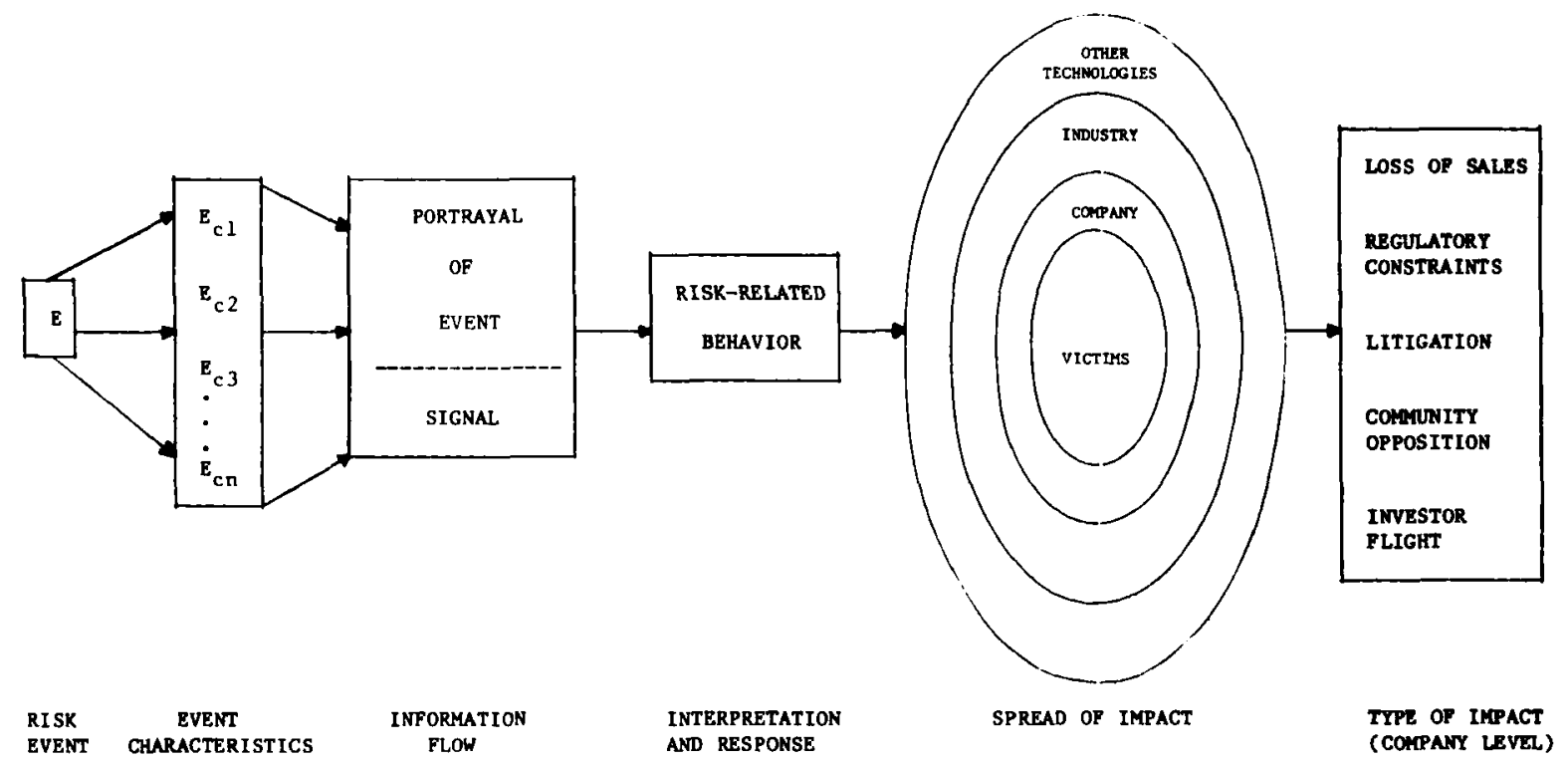

Fig. 1. Highly simplified representation of the social amplification of risk and potential impacts on a corporation.

and risk events undergo more or less amplification or attenuation. Whether such a theory will carry the power to predict the specific kinds of public responses and the anatomy of social controversy that will follow the introduction of new risks must await the test of time. It may prove possible to identify and classify attributes of the risk source and of the social arena that heighten or attenuate the public response to risk.

Social amplifications of risk will spawn behavioral responses, which, in turn, will result in secondary impacts. Secondary impacts include such effects as the following:

- Enduring mental perceptions, images, and attitudes (e.g., antitechnology attitudes, alienation from the physical environment, social apathy, stigmatization of an environment or risk manager);

- Local impacts on business sales, residential property values, and economic activity;

- Political and social pressure (e.g., political demands, changes in political climate and culture);

- Changes in the physical nature of the risk (e.g., feedback mechanisms that enlarge or lower the risk);

- Changes in training, education, or required qualifications of operating and emergencyresponse personnel;
- Social disorder (e.g., protesting, rioting, sabotage, terrorism);

- Changes in risk monitoring and regulation;

- Increased liability and insurance costs;

- Repercussions on other technologies (e.g., lower levels of public acceptance) and on social institutions (e.g., erosion of public trust).

Secondary impacts are, in turn, perceived by social groups and individuals so that another stage of amplification may occur to produce third-order impacts. The impacts thereby may spread, or "ripple," to other parties, distant locations, or future generations. Each order of impact will not only disseminate social and political impacts but may also trigger (in risk amplification) or hinder (in risk attenuation) positive changes for risk reduction. The concept of social amplification of risk is hence dynamic, taking into account the learning and social interactions resulting from experience with risk.

The analogy of dropping a stone into a pond (see Fig. 1) serves to illustrate the spread of the higher-order impacts associated with the social amplification of risk. The ripples spread outward, first encompassing the directly affected victims or the first group to be notified, then touching the next higher institutional level (a company or an agency), and, in more extreme cases, reaching other parts of the industry or other social arenas with similar problems. This rippling of impacts is an important ele- 


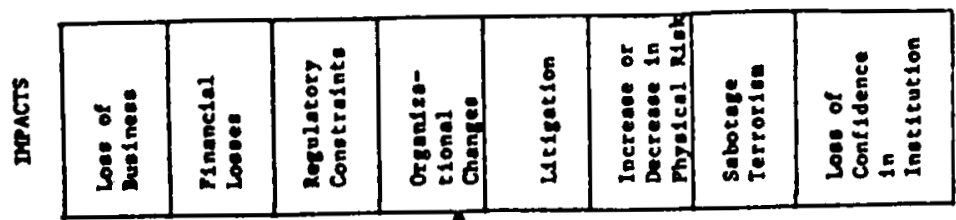
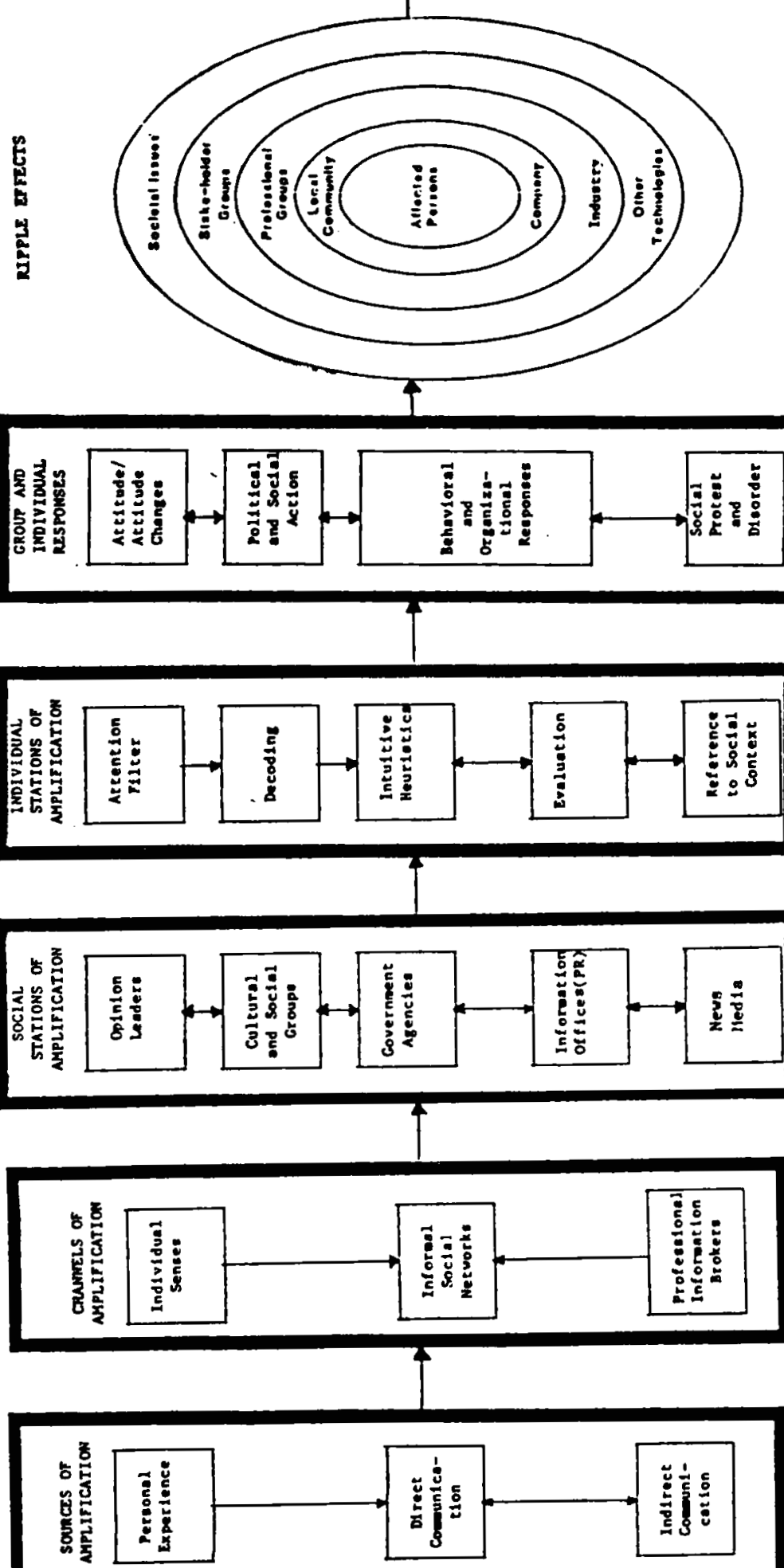
ment of risk amplification since it suggests that amplification can introduce substantial temporal and geographical extension of impacts. The same graphic representation demonstrates the possibility that social amplification may, quantitatively and qualitatively, increase the direct impacts. In this case the inner circle changes it shape with each new round of ripples. Figure 2 depicts in greater detail the hypothesized stages of social amplification of risk and its associated impacts for a hypothetical corporation.

Several examples illustrate the ripple effect of risk events. Following the Three Mile Island accident, nuclear plants worldwide were shut down and restarted more frequently for safety checks, although these phases of operations (as with aircraft takeoffs and landings) are by far the riskiest operational stages. In a more recent case of risk amplification, Switzerland recalled and ordered the incineration of 200 tons of its prestigious Vacherin Mont d'Or cheese because of bacterial contamination. Rival French cheesemakers at first celebrated their good fortune until it became apparent that public concern over the event had caused worldwide consumption of the cheese, from all producers, to plummet by over $25 \%$. An entire industry, in short, suffered economic reversal from a specific risk event. ${ }^{(23)}$

Social amplification of risk, in our current conceptualization, involves two major stages (or amplifiers) - the transfer of information about the risk or risk event, and the response mechanisms of society.

\section{INFORMATIONAL MECHANISMS OF SOCIAL AMPLIFICATION}

The roots of social amplification lie in the social experience of risk, both in direct personal experience and in indirect, or secondary, experience, through information received about the risk, risk events, and management systems. Direct experience with risky activities or events can be either reassuring (as with automobile driving) or alarming (as with tornadoes or floods). Generally, experience with dramatic accidents or risk events increases the memorability and imaginability of the hazard, thereby heightening the perception of risk. ${ }^{(24)}$ But direct experience can also provide feedback on the nature, extent, and manageability of the hazard, affording better perspective and enhanced capability for avoiding risks. Thus, whereas direct personal experience can serve as a risk amplifier, it can also act to attenuate risk.
Understanding this interaction for different risks, for different social experiences, and for different cultural groups is an important research need.

But many risks are not experienced directly. When direct personal experience is lacking or minimal, individuals learn about risk from other persons and from the media. Information flow becomes a key ingredient in public response and acts as a major agent of amplification. Attributes of information that may influence the social amplification are volume, the degree to which information is disputed, the extent of dramatization, and the symbolic connotations of the information.

Independent of the accuracy and particular content of information, large volume of information flow may serve as a risk amplifier. In an analysis of media coverage of Love Canal and Three Mile Island, Mazur argued that the massive quantity of media coverage not only reported the events but defined and shaped the issues. ${ }^{(25)}$ Repeated stories, of course, direct public attention toward particular risk problems and away from competing sources of attention. Moreover, the news media tend to become battlegrounds where various participants vie for advantage. However balanced the coverage, it is unclear that reassuring claims can effectively counter the effects of fear-arousing messages. ${ }^{(26)}$ In Alvin Weinberg's metaphor, it is much harder to "unscare" people than to scare them. ${ }^{(27)}$ High volumes of information also mobilize latent fears about a particular risk and enhance the recollection of previous accidents or management failures or enlarge the extent to which particular failures, events, or consequences can be imagined. In this way, technologies or activities may come to be viewed as more dangerous. ${ }^{(2,28)}$

The second attribute of information is the degree to which individuals or groups dispute factual information or inferences regarded as credible by interested members of the public. Debates among experts are apt to heighten public uncertainty about what the facts really are, increase doubts about whether the hazards are really understood, and decrease the credibility of official spokespersons. ${ }^{(29)}$ If the risks are already feared by the public, then increased concern is the likely result.

Dramatization, a third attribute, is undoubtedly a powerful source of risk amplification. The report during the Three Mile Island accident that a hydrogen bubble inside the reactor could explode within the next two days, blow the head off the reactor, and release radioactive material into the atmosphere certainly increased public fears near the nuclear plant 
(and around the world). Sensational headlines ("Thousands Dead!") following the Chernobyl accident increased the memorability of that accident and the perceived catastrophic potential of nuclear power. If erroneous information sources find ready access to the mass media without effective antidotes, then large social impacts, even for minor events, become entirely possible.

The channels of information are also important. Information about risks and risk events flows through two major communication networks-the news media and more informal personal networks. The news media as risk articulators have received the bulk of scientific attention for their critical role in public opinion formation and community agenda setting. ${ }^{(29,30)}$ Since the media tend to accord disproportionate coverage to rare or dramatic risks, or risk events, it is not surprising that people's estimates of the principal causes of death are related to the amount of media coverage they receive. ${ }^{(31)}$

Informal communication networks involve the linkages that exist among friends, neighbors, and co-workers, and within social groups more generally. Although relatively little is known about such networks, it is undoubtedly the case that people do not consider risk issues in isolation from other social issues or from the views of their peers. Since one's friends or co-workers provide reference points for validating perceptions but are also likely to share a more general cultural view or bias, the potential exists for both amplifying and attenuating information. If the risk is feared, rumor may be a significant element in the formation of public perceptions and attitudes. Within social group interaction, these interpretations of risks will tend to be integrated into larger frames of values and analysis and to become resistant to new, conflicting information. It should be expected, therefore, that interpersonal networks will lead to divergent risk perceptions, management preferences, and levels of concern. Since experts also exhibit cultural biases in their selections of theories, methods, and data, these variable public perceptions will also often differ as a group from those of experts.

Finally, specific terms or concepts used in risk information may have quite different meanings for varying social and cultural groups. They may also trigger associations independent of those intended. ${ }^{(32)}$ Such symbolic connotations may entail "mushroom clouds" for nuclear energy, "dumps" for waste disposal facilities, or feelings of "warmth and comfort" for solar power technologies.

\section{RESPONSE MECHANISMS OF SOCIAL AMPLIFICATION}

The interpretation and response to information flow form the second major stage of social amplification of risk. These mechanisms involve the social, institutional, and cultural contexts in which the risk information is interpreted, its meaning diagnosed, and values attached. We hypothesize four major pathways to initiate response mechanisms:

- Heuristics and Values. Individuals cannot deal with the full complexity of risk and the multitude of risks involved in daily life. Thus people use simplifying mechanisms to evaluate risk and to shape responses. These processes, while permitting individuals to cope with a risky world, may sometimes introduce biases that cause distortions and errors. ${ }^{(28)}$ Similarly, the application of individual and group values will also determine which risks are deemed important or minor and what actions, if any, should be taken.

- Social Group Relationships. Risk issues enter into the political agenda of social and political groups. The nature of these groups will influence member responses and the types of rationality brought to risk issues. ${ }^{(3)}$ To the extent that risk becomes a central issue in a political campaign or in a conflict among social groups, it will be vigorously brought to more general public attention, often coupled with ideological interpretations of technology or the risk-management process. ${ }^{(11,12)}$ Polarization of views and escalation of rhetoric by partisans typically occur and new recruits are drawn into the conflicts. ${ }^{(29)}$ These social alignments tend to become anchors for subsequent interpretations of risk management and may become quite firm in the face of conflicting information.

- Signal Value. An important concept that has emerged from research on risk perception is that the seriousness and higher-order impacts of a risk event are determined, in part, by what that event signals or portends. ${ }^{(4)}$ The informativeness or "signal value" of an event appears to be systematically related to the characteristics of the event and the hazard it reflects. High-signal events suggest that a new risk has appeared or that the risk is different and more serious than previously 
Table I. Risk Events with Potentially High Signal Value

\begin{tabular}{|c|c|}
\hline Events & Messages \\
\hline $\begin{array}{l}\text { Report that chlorofluorocarbon } \\
\text { releases are depleting } \\
\text { the ozone layer }\end{array}$ & $\begin{array}{l}\text { A new and possibly catastrophic } \\
\text { risk has emerged }\end{array}$ \\
\hline $\begin{array}{l}\text { Resignation of regulators or } \\
\text { corporate officials } \\
\text { in "conscience" }\end{array}$ & $\begin{array}{l}\text { The managers are concealing the risks: } \\
\text { they cannot be trusted }\end{array}$ \\
\hline $\begin{array}{l}\text { News report of off-site migration } \\
\text { at a hazardous waste site }\end{array}$ & $\begin{array}{l}\text { The risk managers are not in control } \\
\text { of the hazard }\end{array}$ \\
\hline $\begin{array}{l}\text { Scientific dispute over the validity } \\
\text { of an epidemiological study }\end{array}$ & The experts do not understand the risks \\
\hline $\begin{array}{l}\text { Statement by regulators that the } \\
\text { levels of a particular contaminant } \\
\text { in the water supply involve only } \\
\text { very low risks as compared with } \\
\text { other risks }\end{array}$ & $\begin{array}{l}\text { The managers do not care about the } \\
\text { people who will be harmed; they } \\
\text { do not understand long-term } \\
\text { cumulative effects of chemicals }\end{array}$ \\
\hline
\end{tabular}

understood (see Table I). Thus an accident that takes many lives may produce relatively little social disturbance (beyond that experienced by the victims' families and friends) if it occurs as part of a familiar and wellunderstood system (such as a train wreck). A small accident in an unfamiliar system (or one perceived as poorly understood), such as a nuclear reactor or a recombinant-DNA laboratory, however, may elicit great public concern if it is interpreted to mean that the risk is not well understood, not controllable, or not competently managed, thus implying that further (and possibly worse) mishaps are likely. In sum, signals about a risk event initiate a process whereby the significance of the event is examined. If found to be ominous, these implications are likely to trigger higher-order social and economic impacts.

- Stigmatization. Stigma refers to the negative imagery associated with undesirable social groups or individuals. ${ }^{(33)}$ But environments with heavy pollution, waste accumulation, or hazardous technology may also come to be associated with negative images. Love Canal, the Valley of the Thousand Drums, Times Beach, and the Nevada Test Site evoke vivid images of waste and pollution. Since the typical response to stigmatized persons or environments is avoidance, it is reasonable to assume that risk-induced stigma may have significant social and policy consequences. ${ }^{(34)}$ Research is needed to define the role of risk in creating stigma, the extent of aversion that results, and how durable such stigma become.

In addition to these four mechanisms, positive feedback to the physical risk itself can occur due to social processes. If a transportation accident with hazardous materials were to occur close to a wastedisposal site, for example, protests and attempted blockage of the transportation route could result. Such actions could themselves become initiating or coaccident events, thereby increasing the probabilities of future accidents or enlarging the consequences should an accident occur. Or, alternatively, an accident in waste handling at the facility could lead opponents, or a disgruntled worker, to replicate the event through sabotage. Especially where strong public concern exists over a technology or facility, a wide variety of mechanisms is present by which health and safety risks may be enlarged through social processes. ${ }^{(35)}$

\section{NEXT STEPS}

Only partial models or paradigms exist for characterizing the phenomenon we describe as the social amplification of risk. Understanding this phenomenon is a prerequisite essential for assessing the potential impacts of projects and technologies, for estab- 
lishing priorities in risk management, and for setting health and environmental standards. We put forth this conceptual framework to begin the building of a comprehensive theory that explains why seemingly minor risks or risk events often produce extraordinary public concern and social and economic impacts, with rippling effects across time, space, and social institutions. The conceptualization needs scrutiny, elaboration, and competing views. Empirical studies, now beginning, should provide important tests and insights for the next stage of theory construction.

\section{ACKNOWLEDGMENT}

This work was supported by the Nevada Nuclear Waste Project Office and by NSF grant No. SES 8796182 to Decision Research. We wish to thank Brian Cook, Christoph Hohenemser, Nancy Kraus, Sarah Lichtenstein, Steve Rayner, and three anonymous reviewers for their constructive comments on earlier drafts of the manuscript.

\section{REFERENCES}

1. P. Slovic, B. Fischhoff, and S. Lichtenstein, "Why Study Risk Perception?" Risk Analysis 2, 83-94 (1982).

2. O. Renn, "Risk Perception: A Systematic Review of Concepts and Research Results," in Avoiding and Managing Environmental Damage from Major Industrial Accidents, Proceedings of the Air Pollution Control Association International Conference in Vancouver, Canada, November 1985 (The Association, Pittsburgh, 1986), pp. 377-408.

3. S. Rayner and R. Cantor, "How Fair is Safe Enough? The Cultural Approach to Societal Technology Choice," Risk Analysis 7, 3-13 (1987).

4. P. Slovic, "Perception of Risk," Science 236, 280-290 (1987).

5. C. A. Vlek and P. J. M. Stallen, "Judging Risks and Benefits in the Small and the Large," Organizational Behavior and Human Performance 28, 235-271 (1981).

6. J. M. Doderlein, “Understanding Risk Management," Risk Analysis 3, 17-21 (1983).

7. R. E. Kasperson (ed.), Equity Issues in Radioactive Waste Management (Cambridge, Oelgeschlager, Gunn and Hain, 1983).

8. H. J. Otway and D. von Winterfeldt, "Beyond Acceptable Risk: On the Social Acceptability of Technologies," Policy Sciences 14, 247-256 (1982).

9. B. Wynne, "Public Perceptions of Risk," in The Urban Transportation of Irradiated Fuel, J. Surrey (ed.), (Macmillan, London, 1984), pp. 246-259.

10. B. Fischhoff, P. Slovic, S. Lichtenstein, S. Read, and B. Combs, "How Safe is Safe Enough?: A Psychometric Study of Attitudes Towards Technological Risks and Benefits," Policy Sciences 8, 127-152 (1978).

11. M. Douglas and A. Wildavsky, Risk and Culture: An Essay on the Selection of Technological and Environmental Dangers (University of California Press, Berkeley, 1982).

12. B. Johnson and V. Covello (eds.), Social and Cultural Construction of Risk (Reidel, Boston, 1987).

13. D. von Winterfeldt and W. Edwards, Understanding Public Disputes about Risky Technologies, technical report (Social Science Research Council, New York, 1984).

14. M. T. Katzman, Chemical Catastrophes: Regulating Environmental Risk Through Pollution Liability Insurance (R. D. Irwin, Springfield, Illinois, 1985).

15. C. D. Heising and V. P. George, "Nuclear Financial Risk: Economy Wide Cost of Reactor Accidents," Energy Policy 14, 45-52 (1986).

16. H. I. Sharlin, EDB: A Case Study in the Communication of Health Risk (Office of Policy Analysis, Environmental Protection Agency, Washington, D.C., 1985).

17. I. Hoos, "Risk Assessment in Social Perspective," in Perceptions of Risk (National Council on Radiation Protection and Measurement, Washington, 1980), pp. 37-85.

18. M. L. DeFleur, Theories of Mass Communication (D. McKay, New York, 1966)

19. P. J. Shoemaker, "Mass Communication by the Book; A Review of 31 Texts," Journal of Communication 37(3), 109-131 (1987).

20. H. D. Lasswell, "The Structure and Function of Communication in Society," in L. Bryson (ed.), The Communication of Ideas: A Series of Addresses (Cooper Square Publishers, New York, 1948), pp. 32-35.

21. C. J. Hovland, "Social Communication," in Proceedings of the American Philosophical Society 92, 371-375 (1948).

22. J. H. Sorensen and D. S. Mileti, "Decision-Making Uncertainties in Emergency Warning System Organizations," International Journal of Mass Emergencies and Disasters (in press).

23. S. Grunhouse, "French and Swiss Fight about Tainted Cheese," New York Times (1 January 1988), p. 2.

24. P. Slovic, "Informing and Educating the Public about Risk," Risk Analysis 6, 403-415 (1986).

25. A. Mazur, "The Journalist and Technology: Reporting about Love Canal and Three Mile Island," Minerva 22, 45-66 (1984).

26. J. Sorensen et al., Impacts of Hazardous Technology: The Psycho-Social Effects of Restarting TMI (State University of New York Press, Albany, 1987).

27. A. Weinberg, "Is Nuclear Energy Acceptable?" Bulletin of the Atomic Scientists 33(4), 54-60 (1977).

28. D. Kahneman, P. Slovic, and A. Tversky (eds.), Judgment under Uncertainty: Heuristics and Biases (Cambridge University Press, New York, 1982).

29. A. Mazur, The Dynamics of Technical Controversy (Communication Press, Washington, D.C., 1981).

30. National Research Council, Disasters and the Mass Media (National Academy of Sciences Press, Washington, D.C., 1980).

31. B. Combs and P. Slovic, "Newspaper Coverage of Causes of Death," Journalism Quarterly 56, 837-843, 849 (1979).

32. H. Blumer, Symbolic Interactionism: Perspective and Method (Prentice Hall, Englewood Cliffs, New Jersey, 1969).

33. E. Goffman, Stigma (Prentice Hall, Englewood Cliffs, New Jersey, 1963).

34. P. Slovic, "Forecasting the Adverse Economic Effects of a Nuclear Waste Repository," in R. G. Post (ed.), Waste Management ' 87 (Arizona Board of Regents, University of Arizona, Tuscon, 1987).

35. R. E. Kasperson, J. Emel, R. Goble, C. Hohenemser, J. X. Kasperson, and O. Renn, "Radioactive Wastes and the Social Amplification of Risk," in R. G. Post (ed.), Waste Management ' 87 (Arizona Board of Regents, University of Arizona, Tucson, 1987). 